\title{
Recruitment of scleractinian corals in the Solitary Islands Marine Reserve, a high latitude coral- dominated community in Eastern Australia
}

\author{
Vicki J. Harriott, Simon A. Banks \\ Centre for Coastal Management, Southern Cross University, PO Box 157, Lismore 2480, Australia
}

\begin{abstract}
The Solitary Islands Marine Reserve $\left(30^{\circ} 18^{\prime} \mathrm{S}, 153^{\circ} 30^{\prime} \mathrm{E}\right)$ is the site of the southern-most extensive coral communities on coastal eastern Australia. It has been hypothesised that lack of successful reproduction or recruitment of corals limits the distribution of corals at high latitudes. In this study, coral recruitment patterns were examined for 4 locations within the Solitary Islands Marine Reserve. Hard coral recruitment rate at the Solitary Islands (6.7 recruits per plate pair) was less than rates reported from similar studies at both the Great Barrier Reef (44 to 242 recruits per tile pair) and at Lord Howe Island (48.5 recruits per tile pair). Recruitment was spatially variable both within and between locations, and there was seasonal and inter-annual variability in recruitment success at 1 site. Recruitment of hard corals was dominated by planulating species, consistent with predictions made from coral recruitment patterns at Lord Howe Island, and in contrast with most previous studies of Pacific reefs. At the 2 most offshore islands, coral cover was dominated by Acropora sp., but the density of acroporid recruits was extremely low, suggesting that this taxon may be reliant on sporadic recruitment from northern sites. In contrast with tropical sites where coral recruitment in shallow water is most frequent on downward facing surfaces or crevices, corals settled abundantly on the upper-most surface of settlement plates at most sites. The difference in settlement orientation is possibly because of: (1) reduced light at high latitudes; (2) a reduction in herbivore abundance at high latitudes; (3) competition for settlement space on lower surfaces with abundant temperate species such as bryozoans and barnacles.
\end{abstract}

KEY WORDS: High latitude · Coral recruitment

\section{INTRODUCTION}

Historically, it has been assumed that coral reefs can develop only at tropical latitudes where temperatures only rarely fall below about $18^{\circ} \mathrm{C}$ (Stoddart 1969 , Veron 1974, Hopley 1982, Rosen 1988). It has been hypothesised both that corals cannot survive at lower temperatures (Dana 1843, Wells 1957) and that corals can survive but cannot reproduce in cold water locations (Yonge 1940, Wells 1957). Because of the assumption that corals cannot reproduce in low temperatures, it has been suggested that recruitment in high latitude coral communities may be reliant on the sporadic dispersal of tropical larvae (Veron 1974, Veron et al. 1974 , Veron \& Done 1979, Grigg 1983).

Harriott $(1992,1995)$ investigated coral recruitment at Lord Howe Island (ca $31.5^{\circ} \mathrm{S}$ ), a high latitude Pacific reef, and reported that the recruitment rate of corals was not significantly less than for tropical sites but that recruitment was dominated by the offspring of local corals that brood their larvae. She suggested that this might be because brooded larvae can survive long-distance travel to an isolated reef and because brooded larvae settle rapidly and are more likely to be retained on the reef once a population has been established. There were only very low rates of recruitment that might be attributed to the southern dispersal of tropical coral larvae.

The Solitary Island Marine Reserve lies just off the coastline of eastern Australia, approximately $600 \mathrm{~km}$ south of the Great Barrier Reef. The Reserve includes 5 islands with fringing coral-dominated subtidal communities and is the location of the southern-most extensive coral communities in eastern Australia. A total of 
90 coral species in 28 genera have been recorded from the region (Harriott et al. 1994). While this species number is considerably less than the approximately 356 species recorded for the Great Barrier Reef (Veron 1993), it is greater than the total coral species richness for the Hawaiian Islands (42 species; Grigg 1983) and Caribbean (approximately 50 species; Liddell \& Ohlhorst 1989).

Coral recruitment patterns were examined for 3 islands within the Solitary Islands Marine Reserve, ranging from 3 to $11 \mathrm{~km}$ offshore, and for a rocky reef close to the mainland. The aim of the study was to examine coral recruitment rates at a high latitude site and to test the hypothesis (Harriott 1992) that recruitment at high latitude reefs is dominated by brooding corals. Spatial patterns in recruitment within the region, and temporal patterns of recruitment at a single site, were also investigated.

\section{METHODS}

The Solitary Islands lie between latitudes $30^{\circ} 18^{\prime} \mathrm{S}$ and $29^{\circ} 40^{\prime} \mathrm{S}$ (Fig. 1), close to Australia's most eastern point. The Solitary Islands Marine Reserve encompasses about 100000 ha of coastline and adjacent waters. The islands of the Reserve extend from a few hundred metres to $11 \mathrm{~km}$ from the mainland. Recent surveys found that the scleractinian coral cover ranged from a low of $8.5 \%$ at Muttonbird Island to a high of $50.9 \%$ at South West Solitary Island (Harriott et al. 1994). The major differences between the islands was the increase in species richness at the most northern and offshore islands. The lowest number of species was recorded at Muttonbird Island and Woolgoolga Reef, which are both only a few hundred metres from the shoreline (Harriott et al. 1994).

Scleractinian coral recruitment patterns were investigated following the techniques described in Harriott \& Fisk (1987). Four pairs of ceramic tiles $(15 \times 15 \mathrm{~cm})$ were attached to weldmesh racks secured approximately $15 \mathrm{~cm}$ above the substratum as shown in Fisk \& Harriott (1990). Similar studies have been undertaken in the Great Barrier Reef (Harriott \& Fisk 1988, Fisk \& Harriott 1990), and more recently at Lord Howe Island (Harriott 1992).
The recruitment patterns were investigated at 4 sites in summer 1992/93: Woolgoolga Reef, South West Solitary Island, North West Solitary Island and North Solitary Island (Fig. 1). Studies of both tropical and subtropical reefs have indicated that maximum recruitment occurs during the summer period, and spawning of local corals had been reported in February and March (P. Harrison pers. comm.). Four settlement racks were secured at each site on 3-5 November 1992, with the racks placed at sites 6 to $9 \mathrm{~m}$ deep around the island or reef (Fig. 1). Racks were separated by a distance of 10 to $100 \mathrm{~m}$, depending on the size of the island or reef. Four pairs of settlement plates were positioned on each rack in November, and 2 pairs from each rack were collected and replaced by 2 additional plate pairs on 3-4 February 1993. The aim was to try to separate recruitment which occurred prior to the spawning of local broadcast-spawning corals from that following the local spawning. All settlement plates were collected on 1-4 April 1993 (2 pairs submerged

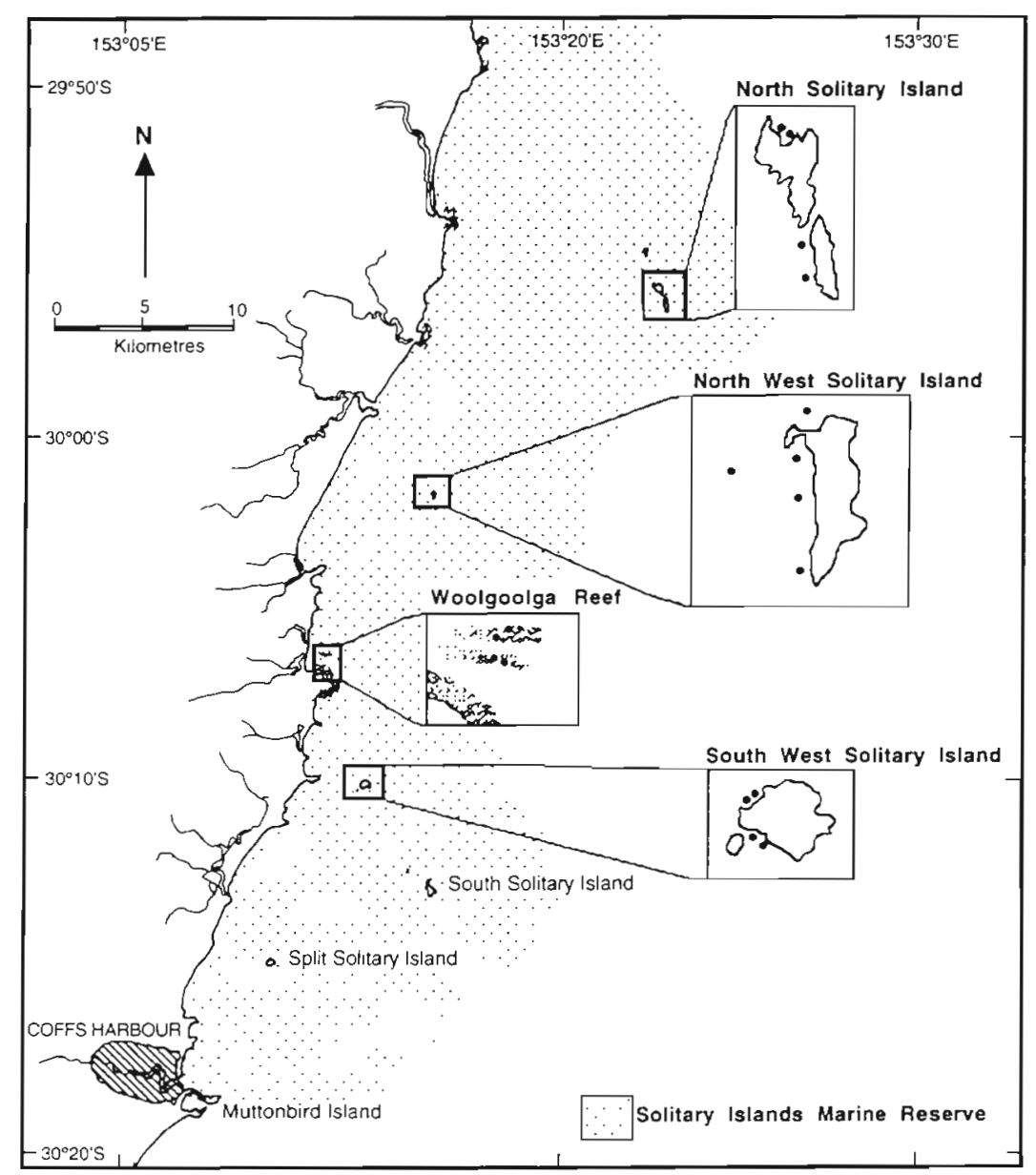

Fig. 1 Positions of settlement racks in the Solitary Islands Marine Reserve, summer 1992/93 
from November to April and 2 pairs submerged from February to April).

Recruitment was investigated over several seasons at South West Solitary Island. In addition to the sets of plates for summer 1992/93 described above, settlement plates were in place during summer 1990/91 (October to March), winter 1991 (Marcl to October), and summer 1991/92 (October to Marcili 2 sites only).

On collection, the settlement plates were labelled and bleached in sodium bypochlorite solution to remove organic material. The tiles were dried and then searched by 2 observers for coral recruits. The corals were marked, mapped and dentified to Family level where possible.

\section{RESULTS}

\section{Density oí recruits}

A total of 190 recruits were found on the settlement plates submerged for a $5 \mathrm{mo}$ period from November 1992 to April 1993 (30 plate pairs at 4 sites). A nested

Table 1. Coral recruitment rate (recruits per tile pair) for 4 sites in the Solitary Islands Marime Reserve, for 3 periods: November 1992 to February 199:3 (N92-F93), February 1993 to April 1993 (F93-A93), November 1992 to April 1993 (N92-393)

\begin{tabular}{|c|c|c|c|c|c|c|}
\hline \multirow{2}{*}{ Family } & \multicolumn{2}{|c|}{ N92-F93 } & \multicolumn{2}{|c|}{ F93-A93 } & \multicolumn{2}{|c|}{ N92-A93 } \\
\hline & Mean & $\mathrm{SD}$ & Mean & $\mathrm{SD}$ & & $\mathrm{SD}$ \\
\hline \multicolumn{7}{|c|}{ North Solitary Island } \\
\hline Pocilloporidae & 5.6 & 2.15 & 0.6 & 0.42 & 3.8 & 1.61 \\
\hline Poritidae & 0.5 & 0.42 & 1.6 & 1.43 & 0.8 & 0.59 \\
\hline Acroporidae & 0.1 & 0.18 & 0.0 & 0.00 & 0.1 & 0.18 \\
\hline Unknown & 1.8 & 1.01 & 0.9 & 0.47 & 0.3 & 0.25 \\
\hline Total & 8.0 & 2.93 & 3.0 & 3.60 & 4.9 & 2.06 \\
\hline \multicolumn{7}{|c|}{ North West Solitary Island } \\
\hline Pocilloporidae & 1.3 & 0.80 & 1.5 & 0.67 & 2.2 & 0.90 \\
\hline Poritidae & 0.0 & 0.00 & 0.3 & 0.27 & 0.6 & 0.53 \\
\hline Acroporidae & 0.0 & 0.00 & 0.0 & 0.00 & 0.0 & 0.00 \\
\hline Unknown & 0.2 & 0.32 & 0.4 & 0.38 & 0.4 & 0.38 \\
\hline Total & 1.5 & 1.05 & 2.2 & 0.79 & 3.2 & 1.40 \\
\hline \multicolumn{7}{|c|}{ South West Solitary Island } \\
\hline Pocilloporidae & 1.8 & 0.99 & 3.5 & 1.50 & 9.5 & 4.23 \\
\hline Ponitidae & 0.3 & 0.25 & 3.4 & 3.34 & 3.8 & 2.33 \\
\hline Acroporidae & 0.0 & 0.00 & 0.0 & 0.00 & 0.1 & 0.18 \\
\hline Unknown & 0.1 & 0.18 & 0.1 & 0.18 & 1.1 & 0.73 \\
\hline Total & 2.1 & 1.12 & 7.0 & 4.29 & 14.5 & 5.89 \\
\hline \multicolumn{7}{|l|}{ Woolgoolga Reef } \\
\hline Pocilloporidae & 0.9 & 0.62 & 0.0 & 0.00 & 0.5 & 0.74 \\
\hline Poritidae & 0.0 & 0.00 & 0.0 & 0.00 & 0.0 & 0.00 \\
\hline Acroporidae & 0.0 & 0.00 & 0.0 & 0.00 & 0.0 & 0.00 \\
\hline Unknown & 0.0 & 0.00 & 0.0 & 0.00 & 0.0 & 0.00 \\
\hline Total & 0.9 & 0.60 & 0.0 & 0.00 & 0.5 & 0.30 \\
\hline
\end{tabular}

1-way ANOVA (racks nested in sites), showed a significant effect of site on recruitment rate $(p=0.001)$. Recruitment rate was highest at South West Solitary Island (14.5 recruits per tile pair), followed by North Solitary Island (4.9 recruits per tile pair) and North West Solitary Island ( 3.2 per tile pair) (Table 1 ). Only 3 recruits in total were recorded from Woolgoolga Reef during this period.

\section{Timing of recruitment}

Recruitment at the 3 offshore island sites was compared on plates collected before and after the local broadcast coral spawning, which took place in February and March 1993 (Table 1). Data were analysed using a nested 2-way ANOVA comparing mean density of recruits for the 2 sample times, for each of the 3 sites, with racks nested in sites. There was a significant interaction between site and time $(p=0.001)$, indicating that the relative rate of recruitment in the 2 times varied between sites. At North Solitary Island, recruitment rate was higher in the November to February period, while at South West Solitary Island, recruitment was greater in the February to March period. Recruitment rate was similar during these 2 periods at North West Solitary Island (Table 1)

\section{Taxonomic patterns}

Of the 391 recruits recorded on all settlement plates in summer 1992/93, the most abundant taxon was the Family Pocilloporidae (66\%) followed by the Family Poritidae (23\%). Only 3 recruits from the Family Acroporidae were recorded $(<1 \%) ; 2$ at North Solitary Island and 1 at South West Solitary Island.

To ascertain the timing of recruitment of the different taxa, results were compared for the November 1992 to February 1993 period and the February to March 1993 period (Table 1). Pocilloporid corals recruited in relatively large numbers during both periods. At all 3 island sites, poritids recruited more abundantly in the later period (41 of 47 recruits). Both acroporid corals recorded on these plates recruited in the earlier period.

\section{Temporal variability}

Results for coral recruitment at South West Solitary Island are available for 3 summers and 1 winter (Table 2). Both the density of recruits and the relative abundance of taxa was highly variable between sample times. There was significant recruitment in the 
Table 2. Inter-annual variation in coral recruitment at South West Solitary Island. (A) Density of recruits per tile pair at each rack.

(B) Taxonomic abundance of recruits. n: number of tile pairs per rack

\begin{tabular}{|c|c|c|c|c|c|c|c|c|c|c|c|c|c|}
\hline \multicolumn{14}{|c|}{ (A) Density of recruits per tile pair } \\
\hline & & \multicolumn{3}{|c|}{ Summer $1990 / 91$} & \multicolumn{3}{|c|}{ Winter 1991} & \multicolumn{3}{|c|}{ Summer $1991 / 92$} & \multicolumn{3}{|c|}{ Summer $1992 / 93$} \\
\hline & & $\mathrm{n}$ & Mean & $\mathrm{SD}$ & $\mathrm{n}$ & Mean & $\mathrm{SD}$ & $\mathrm{n}$ & Mean & $\mathrm{SD}$ & $\mathrm{n}$ & Mean & $\mathrm{SD}$ \\
\hline \multirow[t]{2}{*}{ North side } & Rack 1 & 3 & 21.3 & 7.09 & 2 & 0.0 & 0.00 & 3 & 3.7 & 2.52 & 2 & 5.5 & 3.54 \\
\hline & Rack 2 & 3 & 15.7 & 7.57 & 3 & 0.0 & 0.00 & 4 & 5.0 & 3.61 & 2 & 26.5 & 9.19 \\
\hline \multirow[t]{2}{*}{ South side } & Rack 1 & 2 & 5.5 & 0.71 & 1 & 24 & - & & - & - & 2 & 15.5 & 2.12 \\
\hline & Rack 2 & 2 & 6.0 & 0.00 & 1 & 48 & - & & - & - & 2 & 5.5 & 0.71 \\
\hline \multicolumn{14}{|c|}{ (B) Taxonomic abundance of recruits } \\
\hline & & \multicolumn{3}{|c|}{ Summer $1990 / 91$} & \multicolumn{3}{|c|}{ Winter 1991} & \multicolumn{3}{|c|}{ Summer 1991/92 } & \multicolumn{3}{|c|}{ Summer $1992 / 93$} \\
\hline \multicolumn{2}{|l|}{ Acroporidae } & \multicolumn{3}{|c|}{$7.9 \%$} & \multicolumn{3}{|c|}{$0.0 \%$} & \multicolumn{3}{|c|}{$0.0 \%$} & \multicolumn{3}{|c|}{$0.9 \%$} \\
\hline \multicolumn{2}{|l|}{ Pocilloporidae } & \multicolumn{3}{|c|}{$26.2 \%$} & \multicolumn{3}{|c|}{$100.0 \%$} & \multicolumn{3}{|c|}{$7.7 \%$} & \multicolumn{3}{|c|}{$71.0 \%$} \\
\hline \multicolumn{2}{|l|}{ Poritidae } & \multicolumn{3}{|c|}{$65.9 \%$} & \multicolumn{3}{|c|}{$0.0 \%$} & \multicolumn{3}{|c|}{$92.3 \%$} & \multicolumn{3}{|c|}{$28.0 \%$} \\
\hline \multicolumn{2}{|l|}{ No. of recruits } & \multicolumn{3}{|c|}{126} & \multicolumn{3}{|c|}{72} & \multicolumn{3}{|c|}{26} & \multicolumn{3}{|c|}{107} \\
\hline
\end{tabular}

winter 1991 samples, but these recruits were all very poorly developed and presumably recruited shortly before the plates were collected in October 1991. There was considerable variation between summer samples in both recruitment density at the same sites and in the taxonomic abundance of recruits. Summer 1991/92 showed lower recruitment rates, relative to the other 2 summers, although results are available from only 2 sites for that year. While recruitment in summer 1992/93 was dominated by pocilloporids, in common with the other sites described above, poritids were the most abundant recruit in both other summers.

\section{Orientation of recruits on settlement plates}

Recruits settled to all 3 surfaces (top, gap and bottom) of the tile pairs, at each site (Table 3). In summer $1992 / 93$, between 23 and $46 \%$ of recruits settled on the upper-most surface of the tiles, and 34 to $57 \%$ settled on the lower surface. In earlier summers at South West Solitary Island, there was a greater preference for the upper surface, with 58 and $84 \%$ of recruits recorded on the upper surface in the previous 2 summers.

\section{DISCUSSION}

\section{Comparisons with other sites}

Coral recruitment was reduced in the Solitary Islands Marine Reserve, relative to the results reported from comparable studies on the Great Barrier Reef (Harriott \& Fisk 1988, Fisk \& Harriott 1990). Thus, theories that the success of coral reproduction or recruitment might limit the southern distribution of corals in eastern Australia (Veron 1974, Veron \& Done 1979) are supported by these data.

The recruitment rate was also less at Solitary Islands than that reported for Lord Howe Island (Harriott 1992, 1995), which lies at a similar latitude but further offshore. The low recruitment recorded for the Solitary Islands may be because of its relatively small shallow area and because the Islands are located in a region where the East Australian Current is very strong (Wyrtki 1960). Tropical coral larvae entrained in the East Australian Current have only a low probability of encountering suitable reef substrate at the Solitary Islands because of the relatively small size of the fringing reefs. Locally produced coral larvae which do not

Table 3. Orientation preference $(\%)$ of coral recruits on tile pairs. 'Gap' is the space between the tile pairs, i.e. the lower surface of the top tile and the upper surface of the bottom tile

\begin{tabular}{|lccccc|}
\hline Orientation & $\begin{array}{c}\text { SW Solitary Island } \\
\text { Summer 1990/91 }\end{array}$ & $\begin{array}{c}\text { SW Solitary Island } \\
\text { Summer 1991/92 }\end{array}$ & $\begin{array}{c}\text { SW Solitary Island } \\
\text { Summer 1992/93 }\end{array}$ & $\begin{array}{c}\text { NW Solitary Island } \\
\text { Summer 1992/93 }\end{array}$ & $\begin{array}{c}\text { North Solitary Island } \\
\text { Summer 1992/93 }\end{array}$ \\
\hline Top & $84.3 \%$ & $58.1 \%$ & $43.0 \%$ & $23.2 \%$ & $468 \%$ \\
Gap & $8.2 \%$ & $16.1 \%$ & $6.0 \%$ & $43.5 \%$ & $19.4 \%$ \\
Bottom & $7.5 \%$ & $25.8 \%$ & $52.0 \%$ & $33.3 \%$ & $33.9 \%$ \\
Sample size & 126 & 26 & 107 & 69 & 124 \\
\hline
\end{tabular}


settle very rapidly are likely to be swept long distances relatively quickly by the strong southward-moving currents in the region.

Consistent with the hypothesis of Harriott (1992), recruitment at these high latitude, isolated reefs was dominated by the larvae of brooding coral species. A model developed by Preece \& Johnson (1993) also predicts that brooded coral larvae are favoured as the distance between reefs increases. Pocilloporids are known to release brooded larvae (e.g. Harrigan 1972 , Harriott 1983a), which may be asexually produced (Stoddart 1983). Poritid corals may either release brooded larvae or may spawn gametes (Kojis \& Quinn 1982, Harriott 1983b, Harrison \& Wallace 1990, Richmond \& Hunter 1990). The reproductive pattern of Porites heronensis, the dominant poritid coral at the Solitary Islands, is presently unstudied, but the clumped recruitment pattern of this taxa is consistent with that of brooded larvae which may potentially disperse only short distances (Harriott 1992). Histological examination and aquarium observations will be necessary to elucidate the reproductive mechanism (planulation or spawning gametes) and timing for $P$. heronensis.

Fewer than $1 \%$ of the recruits recorded during the study were from the Family Acroporidae, while these are the dominant coral recruit in several studies on the Great Barrier Reef (reviewed in Harrison \& Wallace 1990). The local mass-spawning corals (sensu Harrison et al. 1984) were observed to spawn at the Solitary Islands during February and March 1993 (Harrison unpubl. data) but failed to recruit in high densities. There was evidence from the longer data set at South West Solitary Island that recruitment of this group might occur at longer time intervals, since in summer $1990 / 9110$ acroporid recruits, representing $8 \%$ of all recruits, were recorded. Maintenance of populations of broadcast-spawning species may therefore depend on their sporadic recruitment success, as suggested by Veron \& Done (1979).

Smith (1992) reported that coral recruitment in Bermuda, a high latitude reef site, was dominated by brooding corals, and he proposed that brooded larvae are favoured because of their ability to settle rapidly. Smith compared recruitment and post-recruitment processes between Pacific and Caribbean locations and found that Caribbean reefs at both low and high latitudes were characterised by recruitment predominantly by brooded larvae, while at most Pacific sites studied at that time, recruits of spawning corals were the most abundant. Results for both Lord Howe Island (Harriott 1992, 1995) and Solitary Islands (present study) demonstrate that the dominance of nonbrooded coral recruits is not necessarily characteristic of the Pacific region.

\section{Temporal recruitment patterns}

Pocilloporid corals were recorded on settlement plates collected in October 1991, as well as on plates submerged from November to February and from February to April, indicating an extended reproductive period for this taxa. This is consistent with previous observations that brooding corals release larvae over a longer period than broadcast-spawning species (Harrison \& Wallace 1990)

Poritid corals did not recruit on the plates collected in October 1991 and occurred in only very small numbers on the plates submerged from November to February. Their spawning period at the Solitary Islands is likely to be shorter than for pocilloporid corals, predominantly between January and March.

Two acroporid larvae recruited in summer 1992/93 before the February-March spawning time, and none recruited following the local spawning. Although these numbers are very low, it suggests that these larvae may have recruited from more northern populations which spawn in earlier months. If so, the local spawning in summer 1992/93 is likely to have resulted in very little successful recruitment for this taxon. The results reported for South West Solitary Island indicate that recruitment of acroporids may be more successful in other years, but there is no evidence yet to suggest whether local recruitment or dispersal from northern sites makes the greatest contribution to recruitment of broadcast-spawning species in the long term.

\section{Spatial patterns}

Recruitment rates within island sites showed great variability. Apart from low recruitment at Woolgoolga Reef, there was no clear pattern which could be related to the geographical location of the sites. The lack of success of recruits from the Family Acroporidae in general, and in particular at North Solitary Island where the adult population is dominated by acroporid corals (Harriott et al. 1994), suggests that the maintenance of the adult population of this taxon is dependent on the sporadic influx of recruits. The East Australian Current dominates water movement in this region (Wyrtki 1960), and it is likely that locally spawned larvae are generally transported away from these reefs in most years. Local corals may be dependent on occasional reversals in current direction, or the development of eddies, to return larvae to their parental reef. Larvae swept to the south are unlikely to find suitable settlement conditions within the optimal 4 to 9 d development time for coral larvae (Babcock \& Heyward 1986) as the East Australian Current frequently moves offshore at around the latitude of the 
Solitary Islands. The lack of currents which can consistently carry tropical larvae further south on the East Australian coast may be a factor accounting for the limitation of significant coral communities to regions north of the Solitary Islands.

\section{Orientation}

In contrast with most studies at shallow tropical sites (Harriott \& Fisk 1987, Fisk \& Harriott 1990, Harrison \& Wallace 1990), corals settled abundantly on the uppermost surface of settlement plates at most sites in the Solitary Islands. In tropical studies, settlement orientation was found to be a function of depth, with corals at deeper sites favouring upper surfaces (reviewed in Harrison \& Wallace 1990), and it has been suggested that reduced light will favour orientation on upper surfaces, while high grazing levels and sedimentation will prevent settlement or kill corals on upper shallow surfaces (Birkeland 1977. Carleton \& Sammarco 1987. Fisk \& Harriott 1990).

These upper surfaces at the Solitary Islands were frequently dominated by the fleshy green algae Ulva spp., with corals settling at the base of the algae. The preference for upper surfaces at this site may be due to a number of factors. First, reduced light at this location may mean that light on the lower-most surface is too low for optimal coral survival and growth. High latitude sites have reduced day length and light intensity relative to low latitude sites. In this area, water conditions are frequently turbid, which further reduces light levels.

Second, the high cover of green algae may be indicative of the reduced significance of grazing pressure by herbivorous organisms in sub-tropical reefs (Hatcher \& Rimmer 1985). Corals might survive better on upper surfaces at these latitudes than they do in the tropics where grazing pressure is intense and very small corals may be accidentally grazed along with the algae. Sammarco \& Carleton (1981) reported increased coral recruitment in areas where establishment of damselfish territories reduced the rate of herbivorous fish grazing.

Third, lower surfaces of settlement plates at the Solitary Islands had a very high cover ( $>70 \%$ ) of non-coral fauna such as bryozoans, ascidians and barnacles (Holmes, Harriott \& Banks unpubl. data). Birkeland (1977) reported a similar finding in the Eastern Pacific and Caribbean, where the rate of growth of cryptic fouling organisms was high and space was fully occupied by these organisms, to the exclusion of coral recruits in areas affected by upwelling. Competition for settlement space or post-settlement mortality through overgrowth by other encrusting organisms may limit coral recruitment on lower surfaces in these inshore, sub-tropical reefs.
Acknowledgements. We thank Steve Smith, Chris Connell, Danny Bucher, Sarah Phillips, Greg Daley, and Darren Richardson for assistance in the field, and David Fisk for comments on the manuscript. This project was funded by Internal Research Grants from Southern Cross University and an ARC grant to V.H.

\section{LITERATURE CITED}

Babcock RC, Heyward AJ (1986) Larval development of certain gamete-spawning scleractinian corals. Coral Reefs 5 : 11.1. -116

Birkeland C (1977) The importance of rate of biomass accumulation in early successional stages of benthic communities to the survival of coral recruits. Proc 3rd int Symp Coral Reefs 1:15-21

Carleton JH, Sammarco PW (1987) Effects of substratum irregularity on success of coral settlement: quantification by comparative geomorphological techniques. Bull mar Sci 40(1):85-98

Dana JD (1843) On the temperature limiting the distribution of corals. Am J Sci 45:130-131.

Fisk DA, Harriott VJ (1990) Spatial and temporal variation in coral recruitment on the Great Barrier Reef: implications for dispersal hypotheses. Mar Biol 107:485-490

Grigg RW (1983) Community structure, succession and development of coral reefs in Hawaii. Mar Ecol Prog Ser 11. $1-14$

Harrigan JF (1972) The planula larva of Pocillopora damicornis: lunar periodicity of swarming and substratum selection behaviour. PhD thesis, University of Hawaii, Honolulu

Harriott VJ (1983a) Reproductive seasonality, settlement and post-settlement mortality of Pocillopora damicornis (Linnaeus) at Lizard Island, Great Barrier Reef. Coral Reefs 2: $151-157$

Harriott VJ (1983b) Reproductive ecology of four scleractinian species at Lizard Island, Great Barrier Reef. Coral Reefs 2 $9-18$

Harriott VJ (1992) Recruitment patterns of scleractinian corals in an isolated sub-tropical reef system. Coral Reefs 11 : $215-219$

Harriott VJ (1995) Is the crown of thorns starfish a threat to the reefs of Lord Howe Island? Aquat Cons: mar Freshwat Ecosystems (in press)

Harriott VJ, Fisk DA (1987) A comparison of settlement plate types for experiments on the recruitment of scleractinian corals. Mar Ecol Prog Ser 37:201-208

Harriott VJ, Fisk DA (1988) Recruitment patterns of scleractinian corals: a study of three reefs. Aust $J$ mar Freshwat Res 39:409-416

Harriott VJ, Smith SL, Harrison PL (1994) Distribution patterns among the coral communities of the Solitary Islands Marine Reserve. Mar Ecol Prog Ser 109:67-76

Harrison PL, Babcock RC, Bull GD, Oliver JK, Wallace CC, Willis BL (1984) Mass spawning in tropical reef corals. Science 223:1186-1189

Harrison PL, Wallace CC (1990) Reproduction, dispersal and recruitment of scleractinian corals. In: Dubinsky Z (ed) Coral reef ecosystems. Elsevier Science Publishers, Amsterdam, p 133-207

Hatcher BG, Rimmer DW (1985) The role of grazing in controlling benthic community structure on a high latitude coral reef: measurements of grazing intensity. Proc 5 th int Coral Reef Congr 6:229-236

Hopley D (1982) The geomorphology of the Great Barrier Reef: Quaternary development of coral reefs. Wiley-Interscience Publ, New York 
Kojis BL, Quinn NJ (1982) Reproductive strategies in four species of Porites (Scleractinia). Proc 4th int Symp Coral Reefs 2:145-151

Liddell WD, Ohlhorst SL (1989) Comparison of Western Atlantic coral reef communities. Proc 6th Int Symp Coral Reefs 3:281-286

Preece AL, Johnson CR (1993) Recovery of model coral communities: complex behaviours from interaction of parame ters operating at different spatial scales. In: Green DG. Bossomaier $\mathrm{T}$ (eds) Complex systems: from biology to computation. IOS Press, Amsterdam, p 69-81

Richmond RH, Hunter CL (1990) Reproduction and recruitment of corals: comparisons among the Caribbean, the Tropical Pacific, and the Red Sea. Mar Ecol Prog Ser 60 $185-203$

Rosen BR (1988) Progress, problems and patterns in the biogeagraphy of reef corals and other tropical organisms. Helgoländer Meeresunter 42:269-301

Sammarco PW, Carleton JH (1981) Damselfish territoriality and coral community structure: reduced grazing, coral recruitment, and effects on coral spat. Proc 4 th int Symp Coral Reefs 2:525-535

This article was submitted to the editor
Smith SR (1992) Patterns of coral recruitment and post-settlement mortality on Bermuda's reefs: comparisons to Caribbean and Pacific Reefs. Am Zool 32:663-673

Stoddart D (1969) Ecology and morphology of recent coral reefs. Biol Rev 44:433-498

Stoddart J (1983) Asexual production of planulae in the coral Pocillopora damicornis. Mar Biol 76:279-284

Veron JEN (1974) Southern geographic limits to the distribution of Great Barrier Reef corals. Proc 2nd int Symp Coral Reefs 2:465-473

Veron JEN (1993) A biogeographic database of hermatypic corals. Aust Inst mar Sci Monogr Ser 10

Veron JEN, Done TJ (1979) Corals and coral communities of Lord Howe Island. Aust J mar Freshwat Res 30:203-236

Veron JEN, How RA, Done TJ, Zell L.D, Dodkin MJ, O'Farrell AF (1974) Corals of the Solitary Islands, Central New South Wales. Aust J mar Freshwat Res 25:193-208

Wells JW (1957) Coral reefs. Mem geol Soc Am 67:609-631

Wyrtki K (1960) Surface circulation in the Coral and Tasman Sea. Aust CSIRO Div Fish Oceanogr Tech Pap 8:2-44

Yonge CM (1940) The biology of reef-building corals. Scient Rep Gt Barrier Reef Exped 1:353-391

Manuscript first received: January 1, 1995

Revised version accepted: February 2,1995 